\title{
Provision of Early Pregnancy Loss Care in New York Federally Qualified Health Centers
}

\author{
Amanda Nagle, BS, Silpa Srinivasulu, MPH, Lisa Maldonado, MA, MPH, and \\ Gabrielle deFiebre, MPH
}

Background: Office-based early pregnancy loss (EPL) care is safe and suitable to Federally Qualified Health Centers (FQHCs); prevalence of provision in FQHCs is unknown.

Methods: We conducted a mailed site-level survey of FQHCs in New York State $(n=405)$. Sites that offered prenatal care were eligible for analysis. Questions included provision of and barriers to providing EPL care options. Content analysis was used for write-in responses to barriers. We conducted bivariate analyses using Fisher's Exact tests and risk ratios to investigate associations between EPL care provision and the independent variables site urbanicity, prenatal clinician type, and ultrasound access.

Results: Of 181 mailings returned, 63 sites were eligible (response rate 44.7\%); 88.9\% provided expectant management, $\mathbf{5 3 . 9} \%$ medication management, and $\mathbf{2 3 . 8} \%$ uterine aspiration. Common barriers included lack of clinical infrastructure, poor ultrasound access, and insufficient training. Some held perceived barriers regarding uterine aspiration. Sites with regular ultrasound access were 1.85 times as likely to provide uterine aspiration as sites without regular ultrasound access (95\% CI, 1.16-2.95).

Conclusions: Few New York FQHCs provided comprehensive EPL care. Supporting FQHCs to overcome barriers may expand access to EPL treatment in primary care and increase continuity and patient centeredness. ( $\mathrm{J}$ Am Board Fam Med 2021;34:238-242.)

Keywords: Early Pregnancy Loss, Maternal and Child Health, Federally Qualified Health Centers, Miscarriage, New York, Pregnancy, Prenatal Care, Primary Health Care, Reproductive Health, Surveys and Questionnaires

\section{Introduction}

Nearly 1 in 5 pregnancies end in early pregnancy loss (EPL), also called miscarriage. ${ }^{1}$ Historically, EPL was managed with operating room surgery under sedation, which is mostly no longer necessary. ${ }^{2}$ Firsttrimester EPL management in office-based settings is safe, effective, and acceptable. ${ }^{3}$ Care includes "watch and wait" (expectant management), medication management, and uterine aspiration with local

This article was externally peer reviewed.

Submitted 9 April 2020; revised 8 June 2020; accepted 11 June 2020.

From the Mailman School of Public Health, Columbia University, New York, NY (AN); Reproductive Health Access Project, New York, NY (SS, LM, GdF).

Funding: This work was supported by a grant from the Grove Foundation. The Grove Foundation did not play a role in study design, collecting, analyzing, and interpreting data, writing the manuscript, nor deciding to submit this article for publication.

Conflict of interest: None.

Corresponding author: Silpa Srinivasulu, MPH, Reproductive Health Access Project, PO Box 21191, New York, NY 10025 (E-mail: silpa@reproductiveaccess.org). anesthesia. Expectant management is highly effective for treating incomplete miscarriage; medication and uterine aspiration are more effective for anembryonic gestation and embryonic demise. ${ }^{4-6}$ All options are safe and effective; therefore, professional medical organizations recommend that patient preference should guide treatment choice., ${ }^{3,7}$ Compared with operating room surgery, many patients prefer uterine aspiration in primary care as it is equally safe, more affordable, and feasible. ${ }^{8,9}$ Comprehensive EPL care in primary care can help maintain continuity of care, as patients who go to emergency rooms may feel unsupported and lack follow-up plans. ${ }^{10}$

Federally Qualified Health Centers (FQHCs) provide affordable health care to 29 million people nationally, and to over 2.2 million people in New York State. They care for underserved populations and reduce barriers, like cost and distance, to services. They are important sources of prenatal care and contribute to reducing prenatal care disparities; FQHC patients nationally have lower rates of low birth 
weight compared with US patients overall. ${ }^{11}$ Most FQHC clinicians are family physicians and advancedpractice clinicians (APCs), like nurse practitioners, physician assistants, and midwives. ${ }^{5}$ Family physicians and APCs in FQHCs are well positioned to increase access to EPL care, as part of comprehensive prenatal care. Their scope of practice includes outpatient procedures and maternal and reproductive health care, including uterine aspiration..$^{12,13}$ However, the proportion of FQHCs providing these services is unknown. This study assesses the provision of EPL management in New York State FQHCs and barriers to providing this care.

\section{Methods}

In 2015, we conducted a cross-sectional study of FQHCs in New York State, using the Health Resources and Services Administration's Uniform Data System to identify sites. We defined clinic sites as the unit of measurement, as health care organizations may manage multiple sites and offer different services at each. This produced a list of 651 FQHC sites.

Only those that provided prenatal care were eligible to complete the core survey. We used information from the Uniform Data System list, that is, name and type of care provided, and online investigating to remove 246 sites that were duplicates, permanently closed, or clearly did not provide prenatal care, such as administrative offices, dental-only sites, and school-based health centers. We mailed the remaining 405 potentially eligible sites a prenotice letter then the paper-based survey, addressed to the medical director. To engage nonresponders, we employed the Dillman mailed survey methodology and contacted nonresponding sites up to 3 more times. ${ }^{14}$

The mailing included a screener on providing prenatal care to determine eligibility. Sites that provided prenatal care were invited to continue the survey. Nonprenatal care sites returned the survey with only the first few screening questions completed. The survey contained questions on sites' practice characteristics and provision of each EPL treatment option. We asked sites that did not provide a particular option to select from a list and/or write-in barriers to offering that care.

Characteristics, EPL provision, and barriers were analyzed using descriptive statistics. We grouped write-in responses for site type into new categories. To assess nonresponse bias, we estimated site counties using address information from the Uniform Data System and conducted chi-square analysis on respondent and nonrespondent site urbanicity. We conducted bivariate analyses using Fisher's Exact tests and risk ratios to investigate associations between the outcomes 1) providing 2 or more EPL management types, and 2) providing uterine aspiration; and the independent variables 1) site urbanicity, 2) OB/GYN as prenatal care clinician, and 3) regular ultrasound access. We used SAS University Edition (SAS Institute, Cary, NC) for quantitative analysis; significance set at $P=.05$.

Content analysis was used to analyze write-in barriers. ${ }^{15}$ Through analysis, we found potential misconceptions and categorized them as "perceived barriers." In this process, we did not intend to evaluate respondents' knowledge of EPL care provision, but to understand how potential misunderstandings may occur. The Institutional Review Board of the Institute for Family Health approved this study.

\section{Results}

Of sites we attempted to contact $(n=405), 181$ mailings were returned with 63 eligible sites completing the screener and main survey and 118 ineligible sites completing only the screener. The survey had a $44.7 \%$ response rate, according to American Association for Public Opinion Research Response Rate, ${ }^{3}$ where the eligibility rate among nonrespondents was assumed to be equal to the eligibility rate among those completing the screener. ${ }^{16}$ Responding sites $(n=118)$ did not differ significantly on urbanicity from those that did not respond $(P=.25)$.

Most respondent sites were urban and had family physicians and/or APCs providing prenatal care (Table 1). Figure 1 illustrates combinations of EPL care options offered at responding sites. Only $22.2 \%$ provided all 3 office-based treatments; uterine aspiration was the least available option. Across EPL management types, respondents frequently mentioned that lack of clinical infrastructure and poor access to ultrasound were major barriers to providing care (Table 2). Sites with regular ultrasound access were 7.2 times as likely to provide 2 or more EPL management options (95\% CI, 2.4321.29) and 1.85 times as likely to provide uterine aspiration (95\% CI, 1.16-2.95) as sites without regular ultrasound access (Table 3 ).

Perceived barriers were identified only within write-in responses to challenges to providing 
Table 1. Attributes of FQHCs in New York State that Provide Prenatal Care $(\mathrm{n}=63)$

\begin{tabular}{lc}
\hline Characteristic & $\mathrm{N}(\%)$ \\
\hline Site type & $58(92.1)$ \\
$\quad$ Primary care & $4(6.3)$ \\
Reproductive health or OB/GYN* & $1(1.6)$ \\
Multi-specialty health center* & \\
Urbanicity (n=61) & $47(77.0)$ \\
Urban & $6(9.8)$ \\
Suburban & $8(13.1)$ \\
Rural & \\
Types of clinicians that provide prenatal care at & \\
each site (n=62) & \\
Advanced-practice clinician (nurse practitioner, & $49(79.0)$ \\
physician assistant, midwife) & \\
Family physicians & $44(71.0)$ \\
OB/GYN & $36(58.1)$ \\
EPL care provision & \\
Expectant management & $56(88.9)$ \\
Medication management & $34(53.9)$ \\
Uterine aspiration & $15(23.8)$ \\
None & $7(11.1)$ \\
Site sees patients who present with suspected EPL & $55(87.3)$ \\
Site has regular access to ultrasound & $30(47.6)$ \\
\hline
\end{tabular}

EPL, early pregnancy loss; FQHC, Federally-Qualified Health Center; OB/Gyn, Obstetrics and Gynecology.

*These sites selected "other site type, please specify" on the survey and self-identified. The research team categorized responses accordingly.

${ }^{\dagger}$ These categories are not mutually exclusive. Respondents may have selected multiple options.

uterine aspiration. Among sites that did not provide uterine aspiration $(n=48), 14.6 \%$ mentioned a perceived barrier. We found 2 themes: clinicians' scope of practice $(n=3)$ and physical space required $(n=4)$. One respondent shared, "[we have] no provider able to do [uterine aspiration]. OB/GYN care [is] handled only by midwives-not in scope of practice." While some sites may not have sufficiently trained APCs, this quote suggests that APCs cannot provide uterine aspiration. Some respondents may be unaware that APCs' scope of practice includes uterine aspiration. In addition, some believed they required an operating room to provide uterine aspiration, as one respondent stated: "no operating room on site."

\section{Discussion}

This study demonstrates that few FQHCs in New York, a state with progressive health care access policies, offer comprehensive EPL management. Many experienced systems and training challenges to provide care. These barriers are not unique to New York FQHCs; previous studies identified similar primary care challenges like clinical training, staff resistance, and ultrasound access. ${ }^{17,18}$ Expanding local training opportunities at sites with higher EPL volume may strengthen clinicians' skills to provide full-scope EPL care in FQHCs. ${ }^{12,19,20}$ One promising model, the Hands-on Reproductive Health Training Center, predominantly trains APCs from New York City FQHCs in long-acting reversible contraception counseling, insertion, and removal, and has shown to strengthen APCs' procedural skills. ${ }^{21}$ In addition, as point-of-care ultrasound in family medicine residencies in FQHCs grows, some clinicians will have more opportunities to develop ultrasonography skills needed for EPL management. ${ }^{22}$

In our study, some sites perceived barriers to comprehensive EPL provision regarding types of clinicians allowed to provide uterine aspiration and infrastructure needs. These challenges are opportunities to educate FQHC staff and build shared values around the importance and feasibility of providing EPL care. For example, Washington State's Residency Training Initiative in Miscarriage Management provides family medicine sites intensive assistance to integrate uterine aspiration for EPL. ${ }^{17}$ Similarly, the Miscarriage Care Initiative supports family physicians to work with all health center staff to resolve misunderstandings, articulate values, and work through steps to implement EPL care. ${ }^{17,23}$ FQHCs may benefit from such programs as they often have limited resources and time to solve these challenges on their own. ${ }^{24}$

Figure 1. Early pregnancy loss (EPL) care in New York federally-qualified health centers (FQHCs).

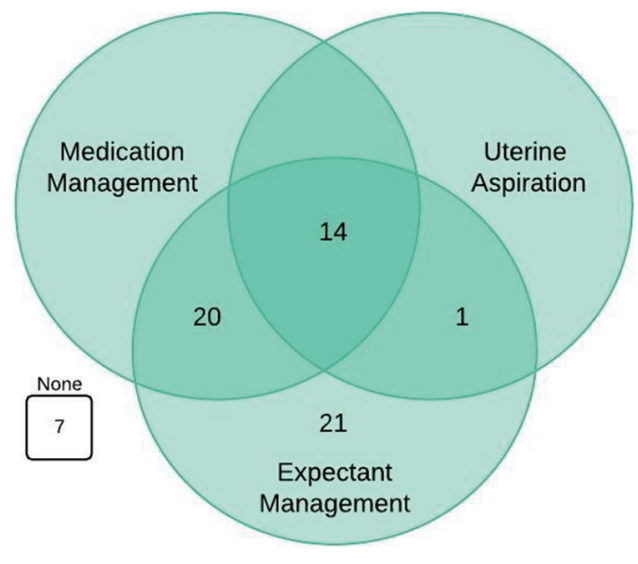


Table 2. Barriers to Providing Comprehensive EPL Care Among New York FQHCs

\begin{tabular}{lccc}
\hline Reasons Why Care Was Not Provided* & $\begin{array}{c}\text { Expectant Management } \\
(\mathrm{n}=7)\end{array}$ & $\begin{array}{c}\text { Medication Management } \\
(\mathrm{n}=29)\end{array}$ & $\begin{array}{c}\text { Uterine Aspiration } \\
(\mathrm{n}=48)\end{array}$ \\
\hline Lack of clinical infrastructure to support care & $71.4 \%$ & $62.1 \%$ & $66.7 \%$ \\
Medication not stocked/no supplies & $\mathrm{N} / \mathrm{A}$ & $65.5 \%$ & $60.4 \%$ \\
No ultrasound access & $71.4 \%$ & $62.1 \%$ & $45.8 \%$ \\
Automatically refer out for this care & $62.1 \%$ & $48.3 \%$ & $58.3 \%$ \\
No clinician trained in EPL care option & $28.6 \%$ & $55.2 \%$ & $47.9 \%$ \\
No trained ultrasound clinician & $28.6 \%$ & $44.8 \%$ & $37.5 \%$ \\
Malpractice insurance does not cover & $28.6 \%$ & $3.4 \%$ & $8.3 \%$ \\
Too similar to abortion care & N/A & $3.4 \%$ & $6.3 \%$ \\
Patient population does not present with EPL needs & $28.6 \%$ & $0 \%$ & $0 \%$ \\
\hline
\end{tabular}

EPL, early pregnancy loss; FQHC, Federally-Qualified Health Center.

*All barriers shown include prespecified options respondents could select from a list.

This study has limitations. Analysis of nonresponse bias was limited by a lack of information about sites that did not return the mailing. We had a moderate response rate and strict eligibility criteria leading to a small sample for analysis. As such, some FQHCs that did not provide prenatal care could have offered EPL management or faced barriers similar to or different from prenatal care sites. The interpretation of perceived barriers is inherently subjective and limited by respondents' details. Findings may not be generalized outside of New York.
Despite limitations, this study estimates the prevalence of EPL care in New York State FQHCs. Though few provided all options, doing so is safe, effective, acceptable, and within the FQHC scope of care. ${ }^{3}$ Offering comprehensive EPL management in FQHCs is an important component of patient-centered care, as it enhances continuity, reduces burdens to find care elsewhere, and allows patients to actively decide how to manage their EPL, improving health outcomes. ${ }^{25}$ Expanding clinical training opportunities and working with FQHC staff to address systems

Table 3. Bivariate Analysis of New York State FQHC Characteristics and EPL Management Provision

\begin{tabular}{|c|c|c|c|}
\hline \multirow[b]{2}{*}{ Characteristic } & \multicolumn{2}{|c|}{ Effect Size (n, \% or Risk Ratio) } & \multirow[b]{2}{*}{$P$ or $95 \%$ CI } \\
\hline & $\begin{array}{l}2+\text { EPL Management Options } \\
\text { Provided }(\mathrm{n}=35)\end{array}$ & $\begin{array}{l}0 \text { to } 1 \text { EPL Management } \\
\text { Options Provided }(\mathrm{n}=28)\end{array}$ & \\
\hline \multicolumn{4}{|l|}{ Urbanicity* $^{*}$} \\
\hline Urban & $25(75.8 \%)$ & $22(78.6 \%)$ & 0.82 \\
\hline Suburban & $4(12.1 \%)$ & $2(7.1 \%)$ & - \\
\hline Rural & $4(12.1 \%)$ & $4(14.3 \%)$ & - \\
\hline $\begin{array}{l}\text { OB/GYN providing prenatal } \\
\text { care }\end{array}$ & $\mathrm{RR}=1.26$ & - & $0.80-1.97$ \\
\hline \multirow[t]{2}{*}{ Regular access to ultrasound } & $\mathrm{RR}=7.20$ & - & $2.43-21.29$ \\
\hline & Uterine Aspiration $(\mathrm{n}=15)$ & No Uterine Aspiration Provided $(\mathrm{n}=48)$ & \\
\hline \multicolumn{4}{|l|}{ Urbanicity* } \\
\hline Urban & $9(69.2 \%)$ & $38(79.2 \%)$ & 0.48 \\
\hline Suburban & $1(7.7 \%)$ & $5(10.4 \%)$ & - \\
\hline Rural & $3(23.1 \%)$ & $5(10.4 \%)$ & - \\
\hline $\mathrm{OB} / \mathrm{GYN}$ providing prenatal care & $\mathrm{RR}=0.77$ & - & $0.43-1.39$ \\
\hline Regular access to ultrasound & $\mathrm{RR}=1.85$ & - & $1.16-2.95$ \\
\hline
\end{tabular}

CI, confidence interval; EPL, early pregnancy loss; FQHC, Federally-Qualified Health Center; OB/Gyn, Obstetrics and Gynecology.

${ }^{*}$ Fisher's Exact Test used for urbanicity, missing values $=2$. 
barriers may increase availability of comprehensive EPL care. ${ }^{12,19}$ Future research should explore the extent to which FQHCs nationally provide EPL management and strategies to support them integrate this care into practice.

To see this article online, please go to: http://jabfm.org/content/ 34/1/238.full.

\section{References}

1. Rossen LM, Ahrens KA, Branum AM. Trends in risk of pregnancy loss among US women, 19902011. Paediatr Perinat Epidemiol 2018;32:19-29.

2. Dalton VK, Harris L, Weisman CS, Guire K, Castleman L, Lebovic D. Patient preferences, satisfaction, and resource use in office evacuation of early pregnancy failure. Obstet Gynecol 2006;108:103-10.

3. Prine LW, Macnaughton H. Office management of early pregnancy loss. Am Fam Physician 2011;84: 75-82.

4. Nanda K, Lopez LM, Grimes DA, Peloggia A, Nanda G. Expectant care versus surgical treatment for miscarriage. Cochrane Database Syst Rev 2012;3:CD003518.

5. Weeks A, Alia G, Blum J, et al. A randomized trial of misoprostol compared with manual vacuum aspiration for incomplete abortion. Obstet Gynecol 2005;106:540-7.

6. Bagratee JS, Khullar V, Regan L, Moodley J, Kagoro H. A randomized controlled trial comparing medical and expectant management of first trimester miscarriage. Hum Reprod 2004;19:266-71.

7. Prager S, Dalton VK, Allen RH. Early pregnancy loss. Obstet Gynecol. 2018;132:e197-e207.

8. Westfall JM, Sophocles A, Burggraf H, Ellis S. Manual vacuum aspiration for first-trimester abortion. Arch Fam Med 1998;7:559-62.

9. Tuncalp O, Gülmezoglu AM, Souza JP. Surgical procedures for evacuating incomplete miscarriage. Cochrane Database Syst Rev 2010;8:CD001993.

10. Baird S, Gagnon MD, deFiebre G, Briglia E, Crowder R, Prine L. Women's experiences with early pregnancy loss in the emergency room: a qualitative study. Sex Reprod Healthc 2018;16:113-7.

11. National Association of Community Health Centers. The community health center chartbook. Available from: https://www.nachc.org/wp-content/ uploads/2020/01/Chartbook-2020-Final.pdf.

12. Levi A, Goodman S, Weitz T, et al. Training in aspiration abortion care: an observational cohort study of achieving procedural competence. Int $\mathrm{J}$ Nurs Stud 2018;88:53-9.

13. American Academy of Family Physicians (AAFP). Recommended curriculum guidelines for family medicine residents: Women's health and gynecological care. AAFP reprint no. 282. American Academy of Family Physicians. 2016:1-11. Available from: https:// www.aafp.org/dam/AAFP/documents/medical_ education_residency/program_directors/Reprint282_ Women.pdf.

14. Dillman DA, Smyth JD, Christian LM. Internet, mail, and mixed-mode surveys: the tailored design method. 3rd ed. Hoboken, NJ: John Wiley \& Sons Inc; 2014.

15. Hsieh HF, Shannon SE. Three approaches to qualitative content analysis. Qual Health Res 2005;15: 1277-88.

16. Smith T. A revised review of methods to estimate the status of cases with unknown eligibility. Available from: www.aapor.org/AAPOR_Main/media/MainSite Files/ERATE09.pdf. Accessed 18 May 2020.

17. Darney BG, Weaver MR, VanDerhei D, Stevens NG, Prager SW. "One of those areas that people avoid:" a qualitative study of implementation in miscarriage management. BMC Health Serv Res 2013;13:123.

18. Dennis A, Fuentes L, Douglas-Durham E, Grossman D. Barriers and facilitators of moving miscarriage care out of the operating room. Perspect Sex Reprod Health 2015;47:141-9.

19. Coffman M, Wilkinson E, Jabbarpour Y. Despite adequate training, only half of family physicians provide women's health care services. J Am Board Fam Med 2020;33:186-8.

20. Stulberg DB, Monast K, Dahlquist IH, Palmer K. Provision of abortion and other reproductive health services among former Midwest Access Project trainees. Contraception 2018;97:341-5.

21. Rubin SE, Maldonado L, Fox K, Rosenberg R, Wall J, Prine L. Establishing and conducting a regional, hands-on long-acting reversible contraception training center in primary care. Womens Health Issues 2018;28:375-8.

22. Bornemann P, Barreto T. Point-of-care ultrasonography in family medicine. Am Fam Physician 2018;15: 200-2.

23. Srinivasulu S, Riker L, Maldonado L, Breitbart V. Evaluation of the miscarriage care initiative: A program to integrate comprehensive early pregnancy loss management in primary care settings. Fam Med 2020;52(10):707-715.

24. Kulesher RR. Health reform's impact on Federally Qualified Community Health Centers: the unintended consequences of increased Medicaid enrollment in the primary care medical home. Health Care Manag (Frederick) 2013;32:99-106.

25. Wieringa-De Waard M, Hartman EE, Ankum WM, Reitsma JB, Bindels PJ, Bonsel GJ. Expectant management versus surgical evacuation in first trimester miscarriage: health-related quality of life in randomized and non-randomized patients. Hum Reprod 2002;17:1638-42. 